\title{
Online Labour Index 2020: New ways to measure the world's remote freelancing market
}

Big Data \& Society

July-December: I-7

(C) The Author(s) 2021

Article reuse guidelines:

sagepub.com/journals-permissions

DOI: 10.1 177/205395|72|11043240

journals.sagepub.com/home/bds

@SAGE

\author{
Fabian Stephany ${ }^{1,2}$ (D), Otto Kässi ${ }^{3}$, Uma Rani ${ }^{4}$ \\ and Vili Lehdonvirta'
}

\begin{abstract}
The Online Labour Index (OLI) was launched in 2016 to measure the global utilisation of online freelance work at scale. Five years after its creation, the OLI has become a point of reference for scholars and policy experts investigating the online gig economy. As the market for online freelancing work matures, a high volume of data and new analytical tools allow us to revisit half a decade of online freelance monitoring and extend the index's scope to more dimensions of the global online freelancing market. While (still) measuring the utilisation of online labour across countries and occupations by tracking the number of projects and tasks posted on major English-language platforms, the new Online Labour Index 2020 (OLI 2020) also tracks Spanish- and Russian-language platforms, reveals changes over time in the geography of labour supply and estimates female participation in the online gig economy. The rising popularity of software and tech work and the concentration of freelancers on the Indian subcontinent are examples of the insights that the OLI 2020 provides. The OLI 2020 delivers a more detailed picture of the world of online freelancing via an interactive online visualisation updated daily. It provides easy access to downloadable open data for policymakers, labour market researchers, and the general public (www.onlinelabourobservatory.org).
\end{abstract}

\section{Keywords}

Online labour markets, gig work, platform economy, online data collection

\section{Introduction}

Since its launch in 2016, the Online Labour Index (OLI) has provided data and visualisations on the online gig economy to researchers, policymakers, and journalists (Kässi and Lehdonvirta, 2018). We initially developed the OLI as a proof-of-concept with a limited scope. In particular, we tracked data only from large English-language platforms. Although large English-language platforms dominate the overall online freelancing market, there are also important regional markets in other languages that missed our focus. We also did not attempt to visualise many of the temporal dynamics of the market, since we had only been accumulating data for a short time, and we missed data on worker demographics, such as gender.

In this paper, we present the Online Labour Index 2020 (OLI 2020), an updated version of the OLI developed in collaboration with the International Labour Organization (ILO). The OLI 2020 makes use of both accumulated time-series data and newly obtained data on Russian- and Spanish-language freelancing platforms. In addition, newly analysed data allows us to estimate the freelancers' gender breakdown across geographies and occupations. The OLI 2020 is made available on the Internet via the Online Labour Observatory, a collaborative website hosted by the ILO and the Oxford Internet Institute (OII) at the University of Oxford. The findings described in this research note and other insights about the online freelancing market can be explored on www.onlinelabourobservatory.org.

\footnotetext{
'Oxford Internet Institute, University of Oxford, Oxford, UK

${ }^{2}$ Alexander von Humboldt Institute for Internet and Society, Berlin, Germany

${ }^{3}$ ETLA, Research Institute of the Finnish Economy, Helsinki, Finland

${ }^{4}$ International Labour Office, Geneva, Switzerland
}

\section{Corresponding author:}

Fabian Stephany, Oxford Internet Institute, University of Oxford, Oxford, UK; Alexander von Humboldt Institute for Internet and Society, Berlin, Germany.

Email: fabian.stephany@oii.ox.ac.uk 


\section{Background}

The online gig economy-also known as the online labour market or online freelancing market-is understood as the market consisting of platform-mediated work that is conducted remotely via the Internet. Instead of hiring a standard employee or contracting with a conventional outsourcing firm, companies are using online labour platforms to find, hire, supervise, and pay workers on a project, piece-rate, or hourly basis. Enterprises from small to large are using these platforms to access skills and flexible labour, assisted by specialised consultants and online outsourcing firms. Dozens of platforms have appeared to cater to different types of clients, workers, and projects, ranging from deskilled microtasks to complex technical projects and professional services. Tens of millions of workers are thought to have sought employment through such platforms (Kuek et al., 2015). ${ }^{1}$

Over the past few years, the online gig economy has matured somewhat. Most of the major online labour platform companies have consolidated and are listed on stock exchanges via initial public offering, including Upwork, Fiverr, and Freelancer. Recent data from selected countries suggests that while platform-mediated remote work is still not a large part of the labour market in any country, it now has some local economic significance beyond what is captured by traditional labour force surveys (e.g. Bracha and Burke 2021; Kässi et al., 2021; Pesole et al., 2018). The online labour market continues to consolidate, as shown by the merger of the, at times, two most popular platforms Odesk and Elance into UpWork in 2013. However, online labour markets remain to be fragmented and regional-often local-language-platforms continue to thrive at the tail of the global distribution of remote platform work.

One of the defining features of the online gig economy is that it spans beyond national boundaries. Thus, any measurement effort concentrating on a single country will only reveal a part of the online gig economy's economic footprint. Moreover, since a large share of work performed on the online platform occurs in the Global South, it is possible that labour market statistics might fail to capture a considerable share of platform-mediated work (see, e.g. Kinyondo and Pelizzo, 2018; Rani et al., 2021). Motivated in part by this problem to capture workers, the OLI was developed in 2016 as the first economic indicator that provides an online gig economy equivalent to some conventional labour market statistics. Over the last five years, it has been measuring the supply and demand of online freelance labour across countries and occupations by tracking the number of projects and tasks across platforms in real time.

The time-series dimension of the OLI allows us to examine the temporal dynamics of online freelance work at a glance. In the last half decade (2016-2021), demand for online freelance work, measured by the OLI, has increased significantly. In early 2021, roughly $90 \%$ more projects were demanded via online freelance platforms than in mid-2016 when the OLI started (Figure 1). This equals an annual growth rate of $10 \%$, which is significantly higher than changes in national (on-site) labour markets, which have plummeted in many countries as a result of the Covid-19 pandemic.

While there is a clear trend increase in the number of vacancies being posted, there is observable fluctuation. Observable dips are visible around Christmas, New Year and summertime (Global North), which correspond to seasonal dips in business activity in those sectors most heavily using online services. Similarly, the OLI time series is characterised by pronounced growth spurts in spring (AprilJune) and autumn (September-November). These may reflect marketing investments made by major platforms and therefore are probably one-off events. The most pronounced fluctuations on the OLI were tracked in 2020, as a reaction to the global COVID-19 pandemic (Stephany et al., 2020). After an unprecedented drop in demand in March 2020, project requests then spiked to an all-time high in May, followed by a sharp decline in the summer.

\section{New features of the Online Labour Index 2020}

As platform-mediated short-term employment is becoming more popular, online freelance markets have become regionally fragmented. A relevant share of the global online freelance work is mediated via platforms operating in languages other than English. Therefore, in addition to the existing features of the OLI, the new OLI 2020 examines Spanish- and Russian-language platform markets. The OLI 2020 also makes use of OLI's accumulated timeseries data to make it possible for users to examine temporal shifts in online labour demand and supply, such as the continuously rising popularity of technology work. Similarly, novel data analytics present a snapshot estimate of the participation of female freelancers in the market. Data customisation is an additional feature of the OLI 2020, allowing users to download their desired subset of the data in an easily manipulable form for further analysis and visualisation in, for example, Excel.

\section{Russian- and Spanish-language platforms}

With the economic maturation of online freelance platforms, regional markets emerged, driven by language barriers and buyers' preference to satisfy their demand for labour domestically (Borchert et al., 2018). Two of the largest regional submarkets shaped by language and domestic demand, outside of the global, English-language domain, are Spanish- and Russian-language freelance domains. To represent the growing popularity of these 


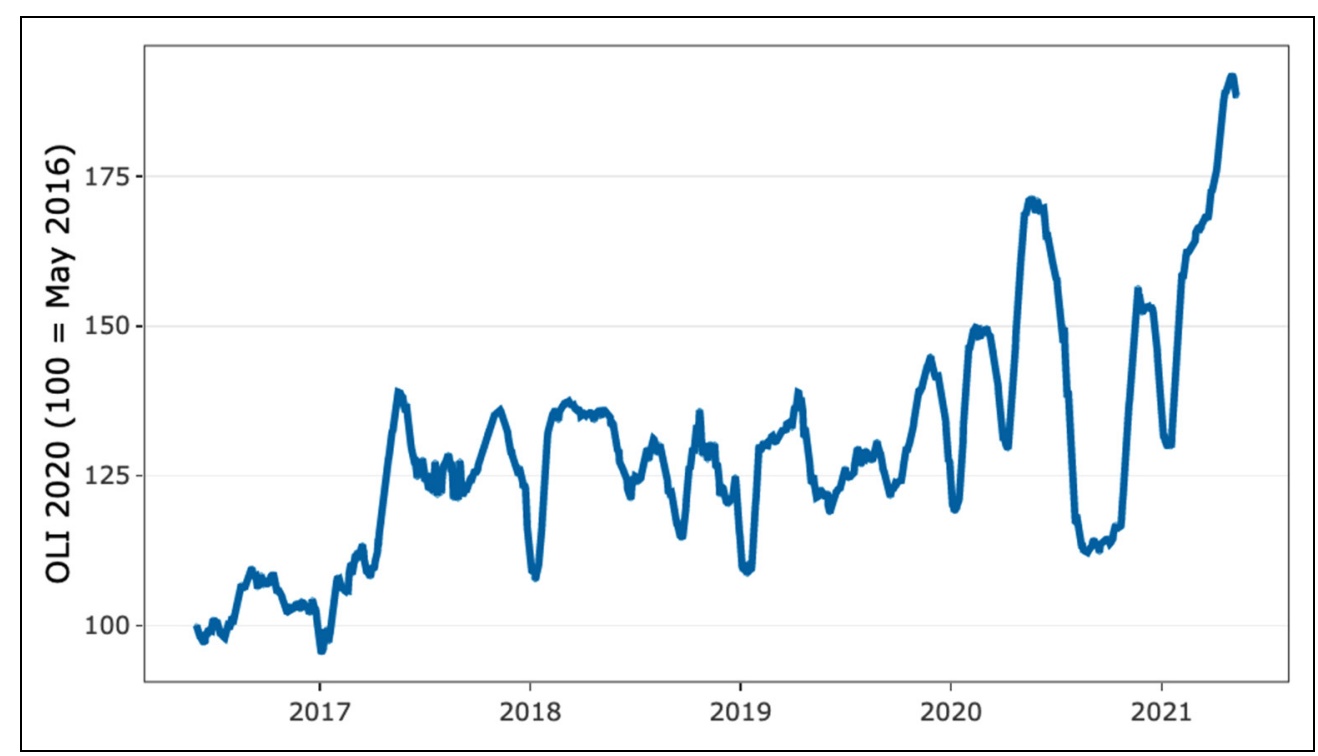

Figure I. Between 2016 and 202I, the OLI registered an overall growth of $90 \%$ in online projects while revealing significant seasonal variability over the last five years.

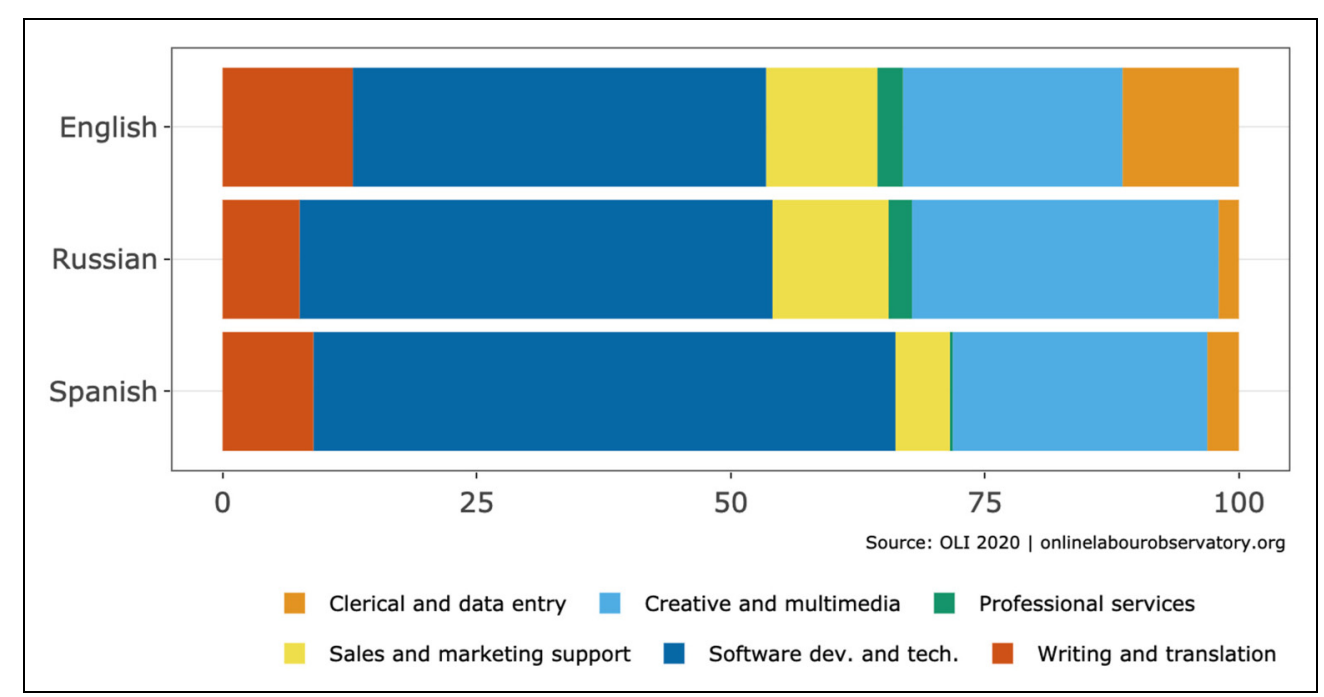

Figure 2. In addition to the original five online freelance platforms, the OLI 2020 tracks the demand of three major Spanish- and Russian-language platforms.

regionally operating online freelance markets, six new platforms have been added $;^{2}$ three from the Spanish-speaking world-freelancer.es, twago.es, and workana.es-and three from the Russian-speaking domain-freelance.ru, freelancehunt.ru, and weblancer.ru. We state that the data from all six newly accessed platforms is solemnly retrieved via the use of web scrapers. Overall, this makes the OLI 2020 less reliable on application programming interface (API) access, as a large share of the platforms monitored since 2016 are likewise accessed via web scrapers. While APIs provide convenient access to data gathered by online platforms, they pose a risk of data disruption, as companies can easily make them closed. The access via web scraping might increase the maintenance effort for the OLI 2020, however, at the same time, it makes the index and users of its data less dependent on access policies imposed by platform providers.

Like its 2016 predecessor, the OLI 2020 is based on tracking all projects and tasks posted on a sample of platforms. Initially, to develop the sample of the OLI, we first collected a list of 40 prominent online labour platforms and retrieved their monthly estimated unique visitor counts from Alexa. ${ }^{3}$ Based on Alexa's figures, we selected the top five platforms, accounting for at least $70 \%$ of all 


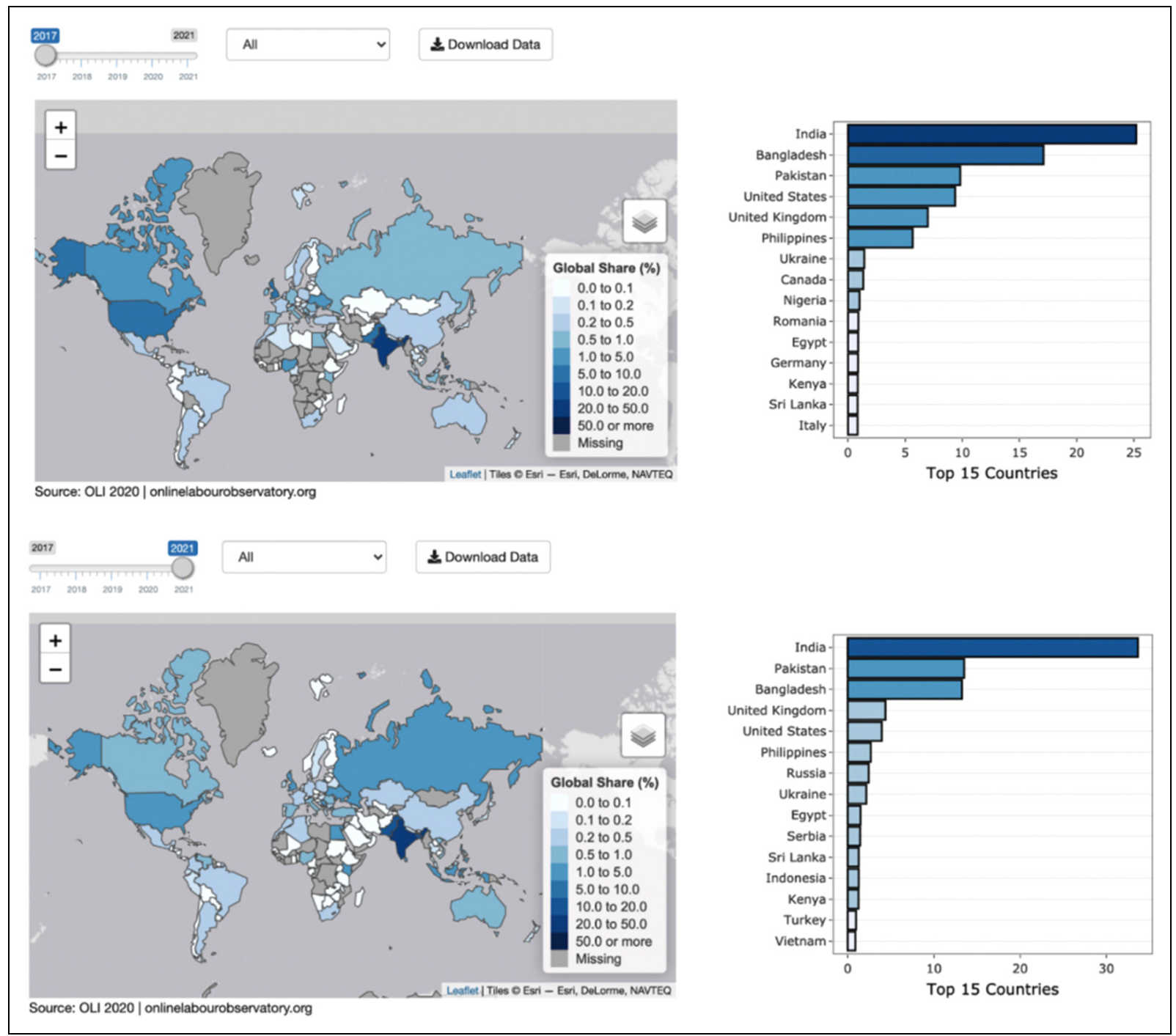

Figure 3. Between 2017 and 202I, the share of online labour supply from India has increased significantly. Now, in 202I, one-third of all freelancers are located in India, and more than half comes from India, Pakistan, and Bangladesh.

traffic to online labour platforms. After English-, Russianand Spanish-language platforms constitute the second and third largest single-language online labour markets. According to Alexa, the six sampled Russian- and Spanish-language platforms are the largest in these markets in terms of traffic popularity.

As illustrated in Figure 2, the new domain-specific features allow users to explore differences across the three online freelance-language markets, such as the significantly larger demand for software and tech work on Spanish-language platforms.

\section{One-third of all freelancers come from India}

Since the beginning of global online freelancing, countries like India, Bangladesh, and Pakistan have been popular digital outsourcing locations because of their workforces' strong English language and tech skills. The OLI 2020 reveals that over the past five years, the share of workers from the Indian subcontinent has only grown. India's share of the global online worker population monitored by the OLI 2020 has grown from $25 \%$ in 2017 to $33 \%$ in 2021. For Bangladesh, the corresponding numbers are $10 \%$ and $15 \%$. This is illustrated in Figure 3, which is produced using OLI 2020's new time-series slider.

\section{Remote software and tech gigs increase}

In the last five years, a striking feature of the geography of online labour utilisation is that the occupational demand profiles of the leading employer countries are rather similar. Employers from all leading buyer countries post most 


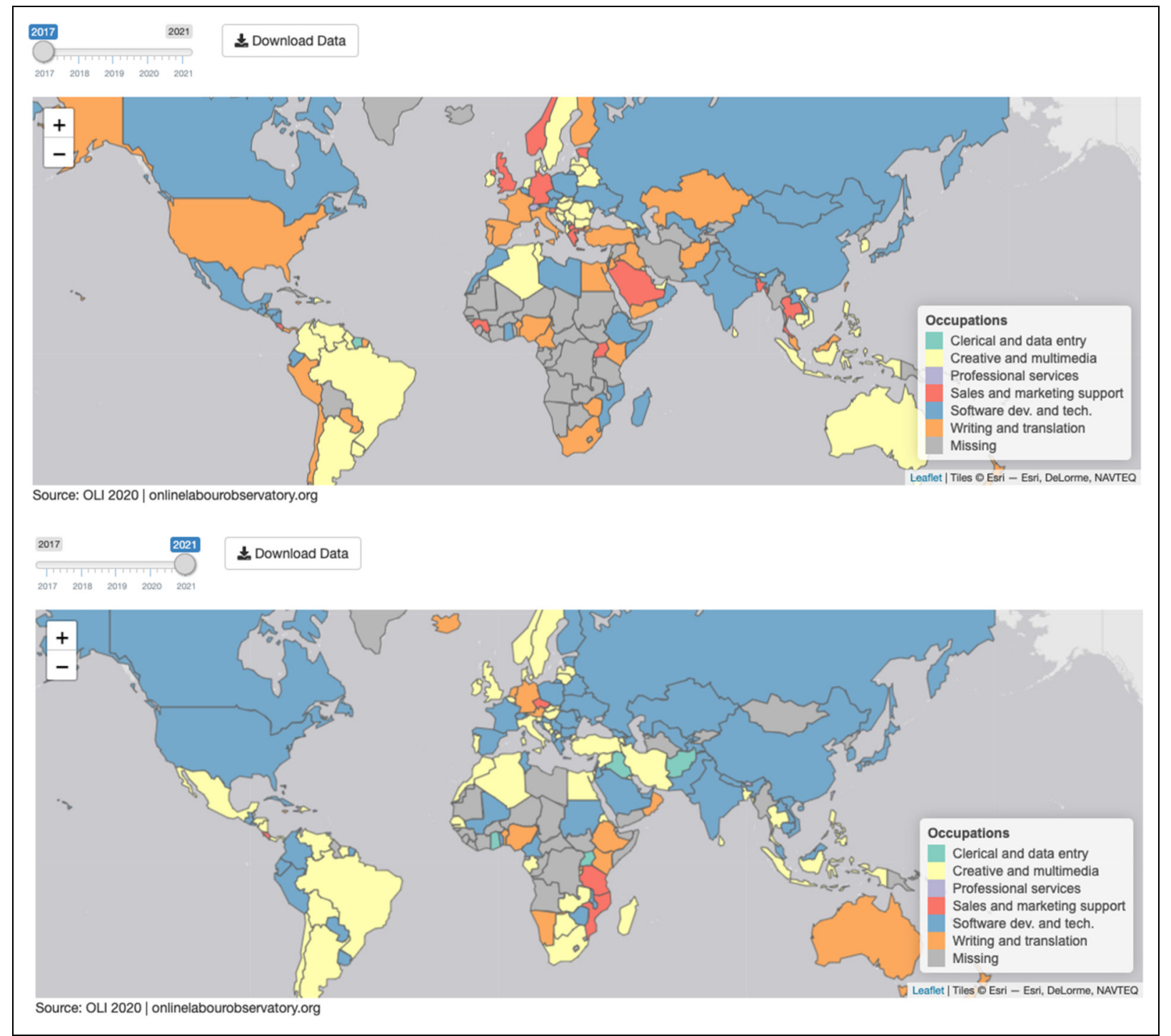

Figure 4. Initially, in 2017, the map of popular freelance occupations was more fragmented. Now, in 2021, software development and tech work have become the most popular domain in many countries.

vacancies in the software development and technology category, followed by creative and multimedia, and so on. This is surprising, because the sectoral and industry structures of these countries are very different, as are the occupational profiles of their conventional domestic labour markets. The fact that they nevertheless resemble each other rather much in online labour demand profiles suggests that the demand largely comes from the same industry within each country: information technology, broadly defined. If industries and sectors start making use of online labour in greater quantities, the OLI should begin to show employer countries' occupational demand profiles diverging.

The new OLI 2020 indicates that this process might have started. Of the six occupational domains categorised by the OLI, technology and software development has been the most popular group globally and across almost all countries. Over the last five years, however, we observe that the share of projects in this domain has been growing even further. Now, in $2021,43 \%$ of all project demand stems from the domain of software development and technology. Similarly, comparing 2017 and 2021, software development and technology has become the most popular freelancing occupation in a number of countries, as shown in Figure 4.

\section{Female participation in the online labour market}

A new feature of the Online Labour Index 2020 is that the index now provides data on the gender breakdown of online labour supply. The gender breakdown estimates are based on guessing worker genders from their given names, drawn from selected tracked platforms. ${ }^{4}$ This is not an 


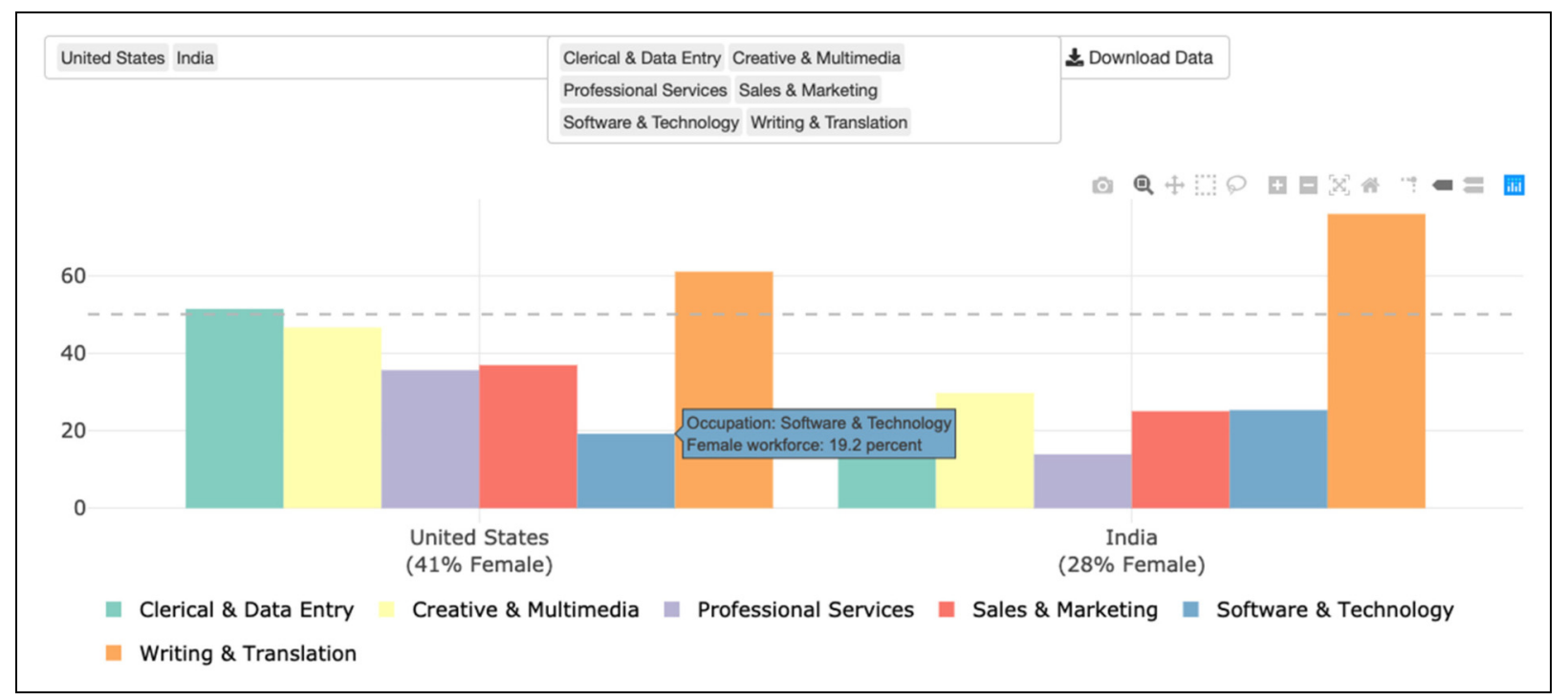

Figure 5. In the United States, a market with $41 \%$ female freelancers, more than half of all freelancers in writing and translation work, are women but less than $20 \%$ of all tech workers are female.

exact method, but it provides a view into a dimension of the market that until now has rarely been examined.

Recently, the role of female gig workers is the subject of online labour studies, for example, with regard to gender stereotypes, differences in pay, and occupational participation (see, e.g. Galperin, 2019). Overall, our data suggest that female workers make up approximately $39 \%$ of the labour supply in the online gig economy. But there are big country differences. The greatest female participation is in the United States, where women make up $41 \%$ of the independent online workforce. In India, the corresponding number is only $28 \%$. This is especially significant given that India is the largest supplier of online labour overall: almost one in three remote platform workers appear to be in India.

But when we break down the United States and Indian online labour supply by occupational category (Figure 5), nuances in female participation emerge. Although overall female participation is lower in India than in the United States, the order is reversed in the software development and technology category. Only one in five remote tech contractors in the United States is female. In India, a quarter of remote tech contractors are female. Participation in tech freelancing thus seems more equal in India than in the United States. Still, in both countries, the largest proportion of women by far is found in writing and translation work, suggesting that online occupations remain somewhat segregated by gender.

\section{Discussion}

Online labour platforms promise to connect jobs with knowledge workers all over the globe (Horton et al., 2017). In bringing jobs and income to people in Global
South countries, they could help to foster more resilient, sustainable local communities (Hjort and Poulsen, 2017) and offer alternatives to the physical migration to places with more jobs and higher wage levels (Braesemann et al., 2020). However, several studies have reported that transactions on online labour platforms are shaped by geographical frictions and biases that restrict participation (Ghani et al., 2014; Braesemann et al., 2021) and that these platforms contribute to the exploitation of a global class of precariously living knowledge workers (Mallett, 2020).

The Online Labour Index 2020 enables a more nuanced view on this highly relevant debate on the economic and social implications of web-based platform work. For example, the OLI 2020 data reveal that online work is strongly fragmented with regard to both geographies (one-third of workers stem from India) and occupations (in $2021,42 \%$ of all work stems from-often well paidsoftware development and tech work.). The OLI 2020, in particular via its new functionalities, serves online workers and their representatives, as it allows them to detect upcoming trends in occupation requests and adjust work portfolios and investments in infrastructure and skills accordingly. In this context, future extensions of the OLI 2020 will most likely make local regions, rather than countries, the smallest geographical unit of analysis to provide an even more nuanced representation of the online gig economy in the future.

\section{Authors' Note}

The corresponding author is likewise affiliated at: Alexander von Humboldt Institute for Internet and Society, Berlin, Germany. 


\section{Declaration of Conflicting Interests}

The author(s) declared no potential conflicts of interest with respect to the research, authorship, and/or publication of this article.

\section{Funding}

The author(s) disclosed receipt of the following financial support for the research, authorship, and/or publication of this article: This work was supported by the H2020 European Research Council (grant number 639652, 875255 ).

\section{ORCID iD}

Fabian Stephany (iD) https://orcid.org/0000-0002-0713-6010

\section{Notes}

1. The OLI 2020, portrayed here, measures the global utilisation of online web-based platform work-tasks or work assignments are performed online or remotely by workers.

2. Without disrupting previous time series, via a chain linking method (https://stats.oecd.org/glossary/detail.asp?ID=5605).

3. https://www.alexa.com/siteinfo

4. For a subsample of 14,838 freelancer profiles from the platforms upwork.com and peopleperhour.com, retrieved between October 2020 and January 2021, we identify the gender of freelancers, by their forename (Blevins and Mullen, 2015).

\section{References}

Blevins C and Mullen L (2015) Jane, john...leslie? A historical method for algorithmic gender prediction. DHQ: Digital Humanities Quarterly 9(3).

Borchert K, Hirth M, Kummer ME, et al. (2018) Unemployment and online labor. ZEW-Centre for European Economic Research Discussion Paper, (18-023). https://dx.doi.org/10. 2139/ssrn.3178692

Bracha A and Burke MA (2021) How big is the gig? The extensive margin, the intensive margin, and the hidden margin. Labour Economics 69: 10-19.

Braesemann F, Lehdonvirta V and Kässi O (2020) ICTs and the urban-rural divide: can online labour platforms bridge the gap? Information, Communication \& Society 1-21.
Braesemann F, Stephany F and Teutloff O, et al. (2020) The polarisation of remote work. https://ssrn.com/abstract= 3913257

Galperin H (2019) "This Gig Is Not for Women": Gender Stereotyping in Online Hiring. Social Science Computer Review. https://doi.org/10.1177/0894439319895757

Ghani E, Kerr WR and Stanton C (2014) Diasporas and outsourcing: Evidence from oDesk and India. Management Science 60(7): 1677-1697.

Hjort J. and Jonas P (2019) The arrival of fast Internet and employment in Africa. American Economic Review 109 (3): 1032-1079.

Horton J, Kerr WR and Stanton C (2018) "3. Digital Labor Markets and Global Talent Flows". In: Hanson GH, Kerr WR and Turner S (eds). High-Skilled Migration to the United States and Its Economic Consequences. Chicago: University of Chicago Press, pp. 71-108. https://doi.org/10. 7208/9780226525662-004

Kässi O and Lehdonvirta V (2018) Online labour index: Measuring the online gig economy for policy and research. Technological Forecasting and Social Change 137: 241-248.

Kässi O, Lehdonvirta V and Stephany F (2021). How many online workers are there in the world? A data-driven assessment. https://arxiv.org/abs/2103.12648

Kinyondo A and Pelizzo R (2018) Poor quality of data in Africa: What are the issues? Politics \& Policy 46(6): 851-877.

Kuek SC, Paradi-Guilford C and Fayomi T, et al. (2015) The Global Opportunity in Online Outsourcing. World Bank, Washington, DC.

Mallett RW (2020) Seeing the "Changing Nature of Work" through a Precarity Lens. Global Labour Journal 11(3): 271-290.

Pesole A, Urzí Brancati MC, Fernández-Macías E, et al. (2018) Platform Workers in Europe, EUR 29275 EN, Publications Office of the European Union, Luxembourg, doi:10.2760/ 742789, JRC112157.

Rani U, Kumar Dhir R, Furrer M, et al. (2021) World Employment and Social Outlook: The Role of Digital Labour Platforms in Transforming the World of Work. International Labour Organisation.

Stephany F, Dunn M, Sawyer S, et al. (2020) Distancing bonus Or downscaling loss? The changing livelihood of Us online workers in times of COVID-19. Tijdschrift voor economische en sociale geografie 111(3): 561-573. 